Proceedings

\title{
Evaluating the Practicality of Spinosad for Use in Packaging Materials $^{+}$
}

\author{
Deanna S. Scheff ${ }^{1, *}$ and James F. Campbell ${ }^{1}$
}

Citation: Scheff, D.S.; Campbell, J.F. Evaluating the Practicality of Spinosad for Use in Packaging Materials, in Proceedings of the 1st International Electronic Conference on Entomology, 1-15 July 2021, MDPI: Basel, Switzerland, doi:10.3390/IECE10364

Published: 30 June 2021

Publisher's Note: MDPI stays neutral with regard to jurisdictional claims in published maps and institutional affiliations.

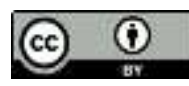

Copyright: (c) 2021 by the authors Submitted for possible open access publication under the terms and conditions of the Creative Commons Attribution (CC BY) license (http://creativecommons.org/licenses /by/4.0/).
1 USDA, Agricultural Research Service, Center for Grain and Animal Health, 1515 College Ave Manhattan, Kansas, USA, 66502 ; Deanna.Scheff@usda.gov

2 USDA, Agricultural Research Service, Center for Grain and Animal Health, 1515 College Ave Manhattan, Kansas, USA, 66502 ; James.Campbell@usda.gov

* Correspondence: Deanna.Scheff@usda.gov; Tel.: +1-785-537-5527

+ Presented at the 1st International Electronic Conference on Entomology (IECE 2021), 1-15 July 2021; Available online: https://iece.sciforum.net/.

\begin{abstract}
Stored product insects are capable of infesting bagged grain commodities causing significant losses. Insecticide treated packaging is an option that may prevent infestations. The objective of this study was to investigate packaging incorporating spinosad alone or in combination with methoprene, on the efficacy against Trogoderma variabile Ballion, warehouse beetle, larvae. There was $100 \%$ suppression of adult emergence from larvae exposed to the combination treatment on cardstock and polymer packaging. The Spinosad only treatment was more effective at inhibiting adult emergence on polymer packaging. This study demonstrated the potential use of spinosad based packaging material to control T. variabile.
\end{abstract}

Keywords: packaging, warehouse beetle, spinosad, methoprene, integrated pest management, organic

\section{Introduction}

Stored product insects are capable of causing significant qualitative and quantitative losses of stored products throughout the entire supply chain. Bagged raw or processed grain and finished products are all susceptible to insect infestation by insects penetrating or invading packaged products. Stored product insects of significant concern include, but not limited to, Plodia interpunctella (Hübner), Indian meal moth, Sitophilus oryzae (L.), rice weevil, Tribolium castaneum Herbst, red flour beetle, and Trogoderma variabile (Ballion), warehouse beetle.

Recent research has been conducted on the impact of insecticide incorporated packaging insect efficacy and penetration/invasion of several stored product insects on methoprene and deltamethrin incorporated packaging [1-5] (Kavallieratos et al., 2017; Scheff et al. 2016, 2017, 2018, 2019). Methoprene has been shown to significantly reduce adult emergence of T. castaneum, T. variabile, and T. granarium larvae exposed to methoprene treated woven and polymer-based packaging materials [2-5] (Scheff et al. 2016, 2017, 2018, 2019). Deltamethrin treated packaging quickly knocks down several adult stored product insects in < 60 minutes [1,6] (Kavallieratos et al. 2017; scheff et al. 2018 (IWCSPP)). These two treatments provide an excellent resource to protect stored products, however they are not viable for the organic foods industry.

Spinosad is a commercially available organic insecticide that has previously been reported to be effective against several stored product insect species when applied topically to grain [7-9]] (Fang et al., 2002; Huang et al., 2004, 2007). However, spinosad's oral toxicity has been reported as being 5-10 times greater than its contact toxicity [10] (Bret et al., 1997). Previous research has demonstrated that concrete, floor tile and steel treated with 
0.05 and $0.1 \mathrm{mg} / \mathrm{cm}^{2}$ spinosad resulted in $>89 \%$ knockdown of eight species of stored product insects after $24 \mathrm{hrs}$. of exposure [11]. However, the use of spinosad in packaging has not been explored or evaluated. The purpose of this experiment is to evaluate spinosad, alone and in combination with methoprene, as a packing treatment to control T. variabile larvae.

\section{Materials and Methods}

\subsection{Insects}

Trogoderma variabile larvae used in this study were obtained from the United States Department of Agriculture's Center for Grain and Animal Health Research in Manhattan, KS, USA. Colonies of T. variabile were reared on dog food (Nestlé Purina PetCare Co., St. Louis, MO, USA) sprinkled with $100 \%$ whole grain oats (Kroger Co., Cincinnati, OH, USA). Colonies were maintained in an environmental growth chamber set at $30^{\circ} \mathrm{C}, 60 \%$ relative humidity (r.h), and 16:8 L:D photoperiod. Larvae used in this study were medium sized larvae, 3-4 $\mathrm{mm}$ in length.

\subsection{Packaging material}

The packaging material used in this study were provided by a commercial manufacture (ProvisionGard ${ }^{\mathrm{TM}}$, Greensboro, NC, USA). Packaging samples consisted of cardstock and polymer packaging. The cardstock packaging was treated with a waterbase coating consisting of a $1 \%$ active ingredient methoprene, $1 \%$ spinosad, or a combination of $1 \%$ methoprene $+1 \%$ spinosad. Thus the treatment combinations were: 1$)$ methoprene only, 2) spinosad only, 3) combo (methoprene + spinosad), or 4) control (untreated packaging).

The polymer packaging consisted of low-density polyethylene film (LDPE) incorporated with 2000 ppm methoprene, 1000 ppm spinosad, or a combination of 2000 ppm methoprene +1000 ppm spinosad. An untreated polyethylene packaging was used as the control.

\subsection{Effect of treated packaging on $\mathrm{T}$. variabile larvae}

All packaging samples (cardstock and polymer) were cut to fit inside a $100 \times 20 \mathrm{~mm}$ $\left(\sim 62 \mathrm{~cm}^{2}\right)$ plastic Petri dish. Packaging was secured on using non-toxic adhesive caulking (DAP Products Inc., Baltimore, MD, USA) and coating the sides with Fluon ${ }^{\circledR}$ (polytetrafluoroethylene, Sigma-Aldrich Co., St. Louis, MO, USA) to prevent insect escape. Fifteen arenas were made for each packaging and treatment type.

Ten T. variabile larvae along with $\sim 500 \mathrm{mg}$ of diet, were added to five individual arenas of methoprene, spinosad, combo, or control packaging respectively, and placed into an environmental chamber set at $27^{\circ} \mathrm{C}$ and $60 \%$ r.h. Observations for normal adult emergence were made weekly, up to four weeks. Additional observations for the number of live and dead larvae, live and dead/deformed pupae, and deformed adults were recorded. Deformed adults include those with missing or deformed body parts, wing deformations, and unsclerotized exoskeleton. This procedure was repeated three times using larvae from different colony jars, thus there were 15 bioassays conducted with a total of 150 individuals for each packaging and treatment combination.

\subsection{Data analysis}

Data for each packaging type were analyzed separately. Data on the percent adult emergence and additional life stage observations, were transformed to angular values before analysis (Zar 2010). The effect of packaging treatment on all life stage observations were compared using a Proc GLM one-way analysis of variance (ANOVA) using Statistical Analysis Software (SAS Institute, version 9.4, 2021) and means were separated using a Tukey's procedure.

\section{Results}


Normal adult emergence was observed all packaging types, except the combo packaging (Figure 1). The control and spinosad only packaging had significantly higher adult emergence compared to all other treatments with 85 and $84 \%$ respectively $(F=154.1 ; \mathrm{df}=$ $3,56 ; P<0.0001)$. Observations on the sub-lethal effects of each packaging found the combo and methoprene packaging had statistically more dead/deformed pupae compared to all other treatments with 38 and $36 \%$ percent respectively $(F=28.7 ; \mathrm{df}=3,56, P<$ $0.0001)$. The combination packaging also had the most live larvae after four weeks after $48 \%$ compared to $7-19 \%$ among all other packaging types.

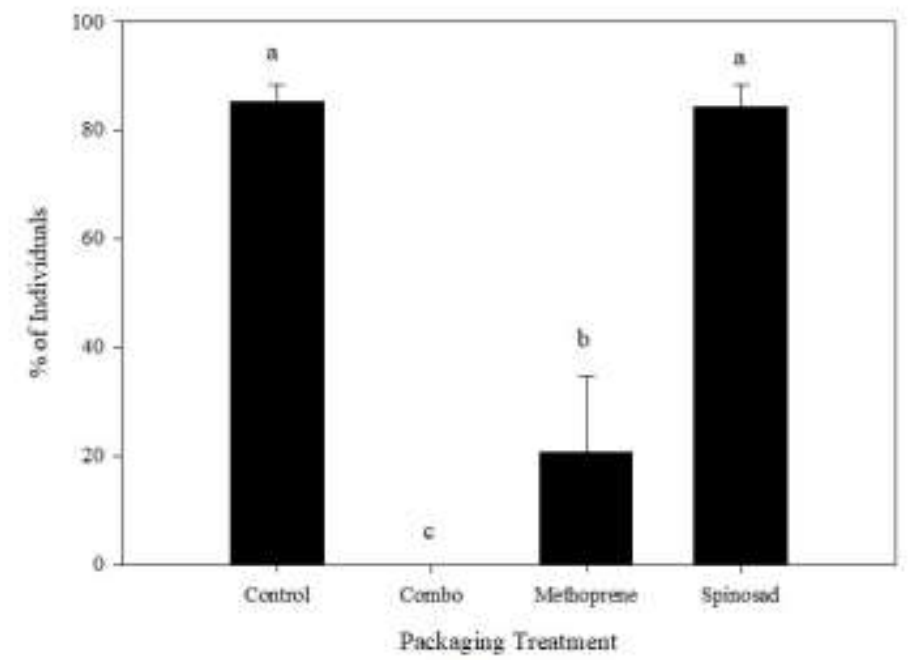

Figure 1. Percent $( \pm$ SE) adult T. variabile emergence from larvae exposed on treated cardstock packaging materials. Different lowercase letters indicate significant differences between the packaging treatments $(P<0.05$; by Tukey's pairwise comparison).

All polymer packaging treatments significantly reduced adult emergence from $T$. variabile larvae exposed to the treated polymer packaging $(F=114.9 ; \mathrm{df}=3,56 ; P<0.0001)$. The control adult emergence was $81 \%$ compared to $38 \%$ on the spinosad packaging, which correlates to a $53 \%$ reduction in adult emergence. Both the methoprene and combination packaging had no adult emergence. Similar to the cardstock packaging, the combo and methoprene packaging had significantly more larvae after four weeks compared to the control and spinosad packaging $(F=100.1 ; \mathrm{df}=3,56 ; P<0.0001)$. The distribution of adult emergence and sub-lethal effects of larvae exposed to the treated packaging is presented in figure 2 


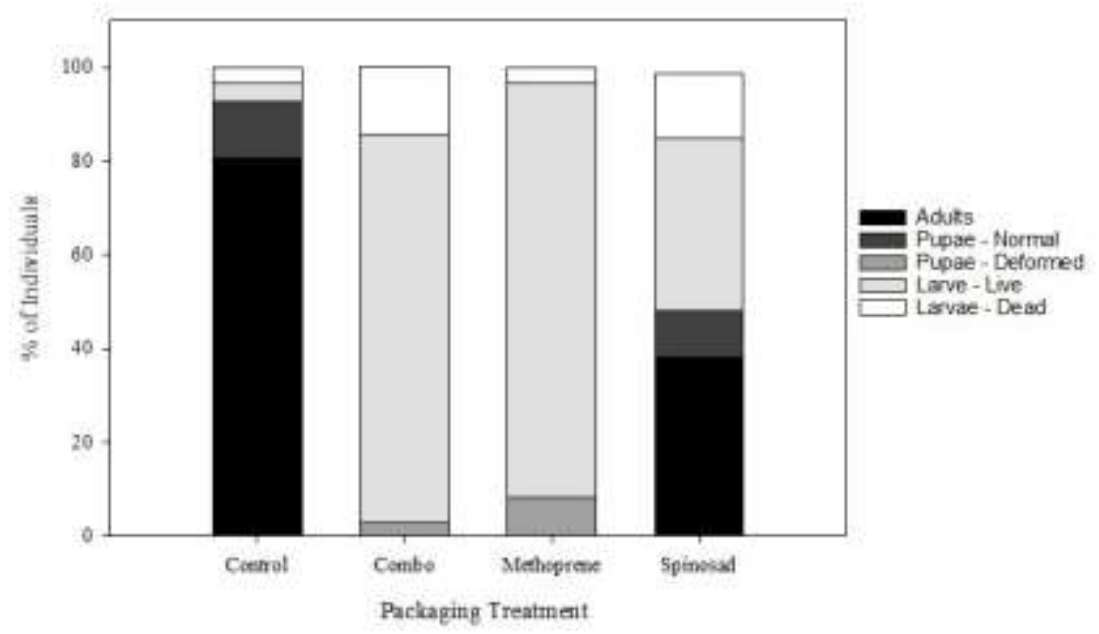

Figure 2. Distribution of $T$. variabile individuals (mean $\pm \mathrm{SE}$ ) after larvae were exposed to treated packaging up to four weeks.

\section{Discussion}

The combination and methoprene packaging had a significant effect on reducing $T$. variabile adult emergence on both paperboard and polymer packaging. However, the spinosad only packaging was most effective when incorporated into the polymer packaging only. The reduction in adult emergence on methoprene treated packaging was expected based on previous research studies [2,3]. The addition of spinosad to the insecticide treatment had a slight synergistic effect, which was observed by complete inhibition of adult emergence after four-weeks of exposure and making this packaging treatment the most effective.

The spinosad only polymer packaging had a 53\% reduction in adult emergence and may be a useful packaging treatment for the organic market. It is currently unclear the significant role the packaging matrix has on spinosad molecule and thus its availability for the insect to uptake. Prior research has shown that the contact efficacy of spinosad requires much greater doses compared to ingested spinosad [11]. The insect's inherent biological component such as larval hairs on T. variabile, may reduce the insect's ability to uptake the insecticide on the outside cuticle. Alternatively, the organic nature of the cardstock could bind the spinosad molecule making it less available to the insect species. Further investigations are required to understand the role of the packaging matrix has on the efficacy of the spinosad compound. In addition, more research is needed on the effect of the combination and spinosad only packaging is needed to ascertain the effect on other stored product insects, effect on different life stages, and residual efficacy.

Ultimately the goal of food packaging is to protect the raw, processed, or finished product within from chemical, biological, and physical hazards. The use of insecticide incorporated packaging can be a tool food processor's use to protect their stored products from insect infestations. Our study was the first to demonstrate the potential for spinosad, an organic insecticide, to be used in packaging material against $T$. variabile. This packaging is a useful tool in the integrated pest management approach to stored grain.

Author Contributions: Conceptualization and methodology, D.S.S., J.F.C.; data collection, analysis, and writing - original draft D.S.S.; writing - review and editing, D.S.S., J.F.C. All authors have read and agreed to the published version of the manuscript.

Funding: ProvisionGard ${ }^{\mathrm{TM}}$ (Greensboro, NC, USA) provided all the packaging samples and partially funded this project.

Institutional Review Board Statement: Not applicable 
Informed Consent Statement: Not applicable

Data Availability Statement: The datasets generated during and/or analyzed during the current study are available from the corresponding author upon reasonable request.

Acknowledgments: We would like to thank the Brain Barnett and Mollie Toth for their excellent technical support. We thank ProvisoinGard ${ }^{\mathrm{TM}}$ for providing the packaging materials used in this research study. Mention of trade names or commercial products in this publication is solely for the purpose of providing specific information and does not imply recommendation or endorsement by the U.S. Department of Agriculture (USDA). The USDA is an equal opportunity provider and employer.

Conflicts of Interest: The authors declare no conflict of interest 


\section{References}

1. Kavallieratos, N.G., Athanassiou, C.G.; Arthur, F.H. Effectiveness of insecticide-incorporated bags to control stored product beetles. J. of Stored Prod. Res. 2017, 70, $18-24$.

2. Scheff, D.S.; Subramanyam, Bh.; Arthur, F.H. Effect of methoprene treated polymer packaging on fecundity, egg hatchability, and egg-to-adult emergence of Tribolium castaneum and Trogoderma variabile. J. Stored Prod. Res. 2016, 69, 227 - 234.

3. Scheff, D.S.; Subramanyam, Bh.; Arthur, F.H. Susceptibility of Tribolium castaneum and Trogoderma variabile larvae and adults exposed to methoprene-treated woven packaging. J. Stored Prod. Res. 2017, 73, $142-150$.

4. Scheff, D.S.; Subramanyam, Bh.; Arthur, F.H.; Dogan, H. 2018. Plodia interpunctella and Trogoderma variabile larval penetration of untreated and methoprene-treated foil packaging. J. Stored Prod. Res. 2017, 78, $74-82$.

5. Scheff, D.S.; Arthur, F.H.; Myers, S.W. 2019. Evaluation of methoprene impregnated packaging against Trogoderma granarium Everts and Trogoderma inclusum LeConte larval development and packaging penetration or invasion into food pouches. J. Stored Prod. Res. 2020, 84: 101530.

6. Scheff, D.S.; Arthur, F.H.; Campbell, J.F. Insecticide treated packaging for the control of stored product insects. In Proceedings of the 12th International Working Conference on Stored Product Protection, October 7-11, 2018, Berlin, Germany, Julius-KuhnArchiv, Berlin, Germany, pp. 920 - 924.

7. Fang, L.; Subramanyam, Bh.; Arthur, F.H.. Effectiveness of spinosad on four classes of wheat against five stored-product insects. J. Econ. Entomol. 2002, 95, $640-650$.

8. Huang, F.; Subramanyam, Bh.; Toews, M.D. Susceptibility of laboratory and field strains of four stored-product insect species to spinosad. J. Econ. Entomol. 2004, 97, 2154-2159

9. Huang, F.; Subramanyam, Bh. Effectiveness of spinosad against seven major grain insects on corn. Insect Sci., 2007, 14, 225-230.

10. Bret, B.L.; Larson, L.L.; Schoonover, J.R.; Sparks, T.C.; Thompson, G.D. Biological properties of spinosad. Down to Earth, 1997, $52,6-13$.

11. Toews, M.D.; Subramanyam, Bh.; Rowan, J.M. Knockdown and mortality of adults of eight species of stored-product beetles exposed to four surfaces treated with Spinosad. J. Econ. Entomol. 2003, 96, $1967-1973$.

12. Zar, J.H. Biostatistical Analysis, 5th ed.; Pearson Prentice-Hall: Upper Saddle River, NJ, USA, 2010. 